Olga N. NOVAK,

Candidate of Philological Sciences (PhD), Associate Professor

of the General and Slavic Linguistics Department, Odessa I. I. Mechnikov National University;

24/26 Francuzskij blvd., Odessa, 65058, Ukraine; tel.: +38 0487760442 ;

e-mail: olganovak2@gmail.com; ORCID ID: 0000-0001-6793-6012

\title{
THE ANALISYS OF THE SEMANTIC VOLUME OF LEXICAL ITEMS TSENNOST" / VREDNOST ("VALUE") IN THE RUSSIAN AND THE SERBIAN LANGUAGES
}

Summary. The article deals with the interrelation of axiology, cultural studies and linguistics. The object of the study is the axionyms which characterise basic human needs and an evaluative (axiological) worldview. The subject of the research is the semantic volume of the lexemes-hyperonyms value in Russian and Serbian languages. The purpose of the study is to analyze the structure and the volume of meaning of the axionyms tsennost' / vrednost (value) in the axiological and interpreting aspects. Multilevel linguistic units and phenomena associated with the vocabulary, word formation, phraseology of Serbian and Russian languages and cultural connotation of the studied units were investigated. The data from thesaurus, etymology dictionary, dictionary of associations were analysed in the research. Finding of research: having conducted a comparative analysis of the semantic volume of the lexemes value in Russian and Serbian languages, we found out that the examined lexemes are not complete equivalents and have different semantic and derivational potential. The Serbian lexeme "vrednost" has wider semantic volume than the lexeme "value" in Russian, besides semes "value" and "price" it includes semes "usefulness", "positive characteristics of a person", "being hardworking", "diligence" etc. The practical value of the research is to use the results of it to optimize the processes of teaching Serbian as a foreign language.

Key words: value, semantic volume, linguaculture, axiological meaning, Serbian language.

Статтю отримано 16.09.2017 p.

http://dx.doi.org/10.18524/2307-4558.2017.28.115865

УДК $811.161 .1 / .2 ’ 373.222 / .421 / .46: 639.2 .052(477)$

ІІУМАРИНА Татьяна Федоровна,

кандидат филологических наук, доцент кафедры русского языка

Одесского национального университета имени И. И. Мечникова;

Французский бульвар, 24/26, Одесса, 65058, Украина; e-mail: shumarina2010@mail.ru;

тел.: +38(048)683539; моб.: +38 067 3779936; ORCID ID: 0000-0001-7383-7707

\section{НОМЕНКЛАТУРНЫЕ СИНОНИМЫ И ВАРИАНТЫ ТАКСОНОВ В ИХТИОЛОГИЧЕСКОЙ СИСТЕМАТИКЕ (НА МАТЕРИАЛЕ НАЗВАНИЙ РЫБ УКРАИНЫ)}

Аннотация. В статье описана терминологическая лексика, используемая в современной украиноязычной и русскоязычной ихтиологической систематике. Цель данной статьи - выявить современные языковые тенденции в национальных (русской и украинской) таксономиях. Объектом изучения в предлагаемой работе стала биологическая номенклатура. Предмет исследования - номенклатурные номинации таксонов рыб Украины. В работе используется описательный и сравнительный методы. В результате исследования определены варианты и синонимы терминов, сходство и отличия в вернакулярных номинациях рыб. Выводы. Наличие абсолютной и частичной синонимии, а также вариантности в обоих языках обусловлено экстралингвистическими и интралингвистическими факторами. Современный процесс унификации и стандартизации названий рыб осложняется вследствие наличия двух противоречащих друг другу тенденций. Ономасиологические тенденции в национальных ихтиологических терминосистемах противоречивы: с одной стороны - это тяготение к аналитическому словообразованию, а с другой - к экономии языковых средств и упрощению семантической и структурной организации ихтионимов. Практическая ценность результатов исследования заключается в возможности их использования в практической и теоретической систематике ихтиофауны Украины.

Ключевые слова: номенклатура, термин, ихтионим, вариант, синоним.

Постановка проблемы. Номенклатурные номинации таксонов ихтиофауны Украины крайне редко оказываются в поле зрения специалистов в области лингвистики. Закономерности образования родовых и видовых названий, ведущие тенденции в области терминологической деривации, критерии унификации ихтионимов определяются единственно специалистами-биологами. Анализ номенклатурного обозначения рыб, населяющих водоёмы Украины, проведённый на материале многочисленных научных источников, позволяет усомниться в достижениях современной систематики.

Как известно, интернациональная ихтиологическая система терминов регулируется Международным кодексом зоологической номенклатуры (2003), принципы которой обеспечивают свободу терминосистем от негативного воздействия полисемии, омонимии, синонимии. Единая латинская 
биологическая номенклатура обеспечивает универсальность и стабильность терминологических номинаций рыб. Иным представляется состояние национальных систематик. Сопоставление фактов даёт основание утверждать наличие многообразия видов языковой вариантности и синонимии в национальных, как русских, так и украинских, терминологических системах. Как представляется, сравнительный подход к современной русской и украинской ихтиологической номенклатуре даст возможность выявить наличествующие немотивированные случаи синонимии, продемонстрировать сходство и отличия в вернакулярных (национальных) номинациях рыб, определить лингвистические тенденции в национальных таксономиях.

Постановка задач. Цель данной статьи - выявить современные языковые тенденции в национальных (русской и украинской) таксономиях. Объектом изучения в предлагаемой работе стала биологическая номенклатура. Предмет исследования - номенклатурные номинации таксонов рыб Украины. В работе используется описательный и сопоставительный методы. Основные задачи исследования заключаются в определении вариантов и синонимов терминов-ихтионимов, установлении сходства и отличий в вернакулярных номинациях рыб.

Изложение основного материала. Синонимия и вариантность в области ихтионимии может быть представлена дихотомично: в интралингвальной и интерлингвальной плоскостях.

Абсолютная и частичная синонимия в области русских ихтионимов ввиду длительности своего существования обросла не только парами, но и синонимическими рядами: румынский пескарь белоперый пескарь, колхидский осётр - чернолорско-азовский осётр, черноморско-каспийская тюлька - иерноморско-азовская тюлька и даже минога карпатская, венгерская, дунайская и под. Аналогичное явление наблюдается и в украинской терминосистеме: плахур - скат, морсъкий жіт - хвостокол звичайний, шип - виз, оселедець чорноморський - оселедець-куцак, карась звичайний - карась золотий, харіус європейсъкий - перій, форель райдужна - пструг райдужний, бичок прозорий - афія, бичок-бабка - бичок-пісочник и, наконец, морсъка лисичя- плахур иипуватий - скат иипуватий.

Особое внимание с учётом глобальной проблемы синонимии и вариантности следует обратить на украинскую систему ихтионимов как относительно молодую, постоянно совершенствуемую и отягощённую терминологическими деривационными процессами. Так, парадигма украинских вариантов видового ихтионима Zosterisessor ophiocephalus составляет четыре компонента: бичож-зелениак, бичок трав'яний, бичок-трав'яник, бичок-трав'яник змієголовий; головешка-ротан - шестью структурно-орфографическими вариантами: ротань-головешка, головешка ротань, головешка Глена, головешка алурсъжа, ротань, ротан. Степень устойчивости данного явления в системе достаточно высока, поскольку варианты отмечаются на большинстве языковых уровней.

Фонематические (орфографические) варианты. Neogobius syrman представлен в украинской систематике следующими вариантами: бичож сірман, бичок-иирман и бичок-сурман. В соответствие с латинской транскрипцией, предпочтение следует отдать одному из первых двух вариантов, а точнее, второму, поскольку эффект омофонии, создаваемый первым, - сірман-сурман - может привести к неразличению видов (бычок-сурман иногда относят к иному виду бычковых). Неудачным, на наш взгляд, является предпочтение варианта сурлан, как и ложноэтимологическая мотивация термина, предлагаемая биологами: “Однією з характерних рис Ponticola syrman $\mathrm{\epsilon}$ чорні (насурмлені) смужки над очима, подібні на брови, звідки й могла виникнути назва „сурман”, яку випадково записали латиною як syrman. Отже, назву „бичок-сурман” пропонуємо використовувати саме для виду Ponticola syrman, оскільки вона відповідає забарвленню риби, а назва латиною $\mathrm{f}$ похідною від української) [1, с. 205].

Выбирая из двух вариантов: бичок-ратан - бичок-ротан (бичож-ротань), - специалисты склоняются к транслитерированной форме с [a], что является лингвистически мотивированным. Возникновение вариантной формы, думается, обусловлено законом аналогии, по которому, вследствие семантико-звуковых ассоциаций с названием рыбы другого, хотя и родственного семейства головешковых - головешка-ротан - возникла омонимичная номинация. Однако решение этого вопроса следует отнести к дискуссионным, поскольку сторонники второй вариантной формы - ротан предлагают свои доводы в пользу формы с [о]: “Назва „бичок-ротань”, яку вживали стосовно цього виду... Можливо, назву вид отримав завдяки забарвленню, яке нагадує кольори ротангу» [1, с. 204].

Кроме вышеназванных причин, как то: ложноэтимологических номинаций, омонимии, закона аналогии, - наличие орфографических вариантов может быть следствием неупорядоченности орфографии (ср. бичок-иучик, бичок-кнут, бичок-кругляк, бичок-пуголовок, бичок-пуголовочок, бичок-лисун, бичок-трав'яник и бичок чучик, бичок ратан, бичок головач, бичок губань, бичок рижик, бичок кругляк, бичок гонечь, бичок сирман, бичок пісочник, бичок кругляч, бичок рись) либо примитивного игнорирования норм правописания, как, например, в названии рыбы nузанож озівсъкий вместо азовсъкий.

Грамматические варианты представлены прежде всего в сфере родових форм: бичок-nуголовочок и пуголовочка, бичок-пуголовож и пуголовка; по этой же модели оформляються и видовые обозначения, тем самым увеличивая число вариантных единиц в украинской таксономии: бичок-nyголовок зіриастий - бичок-пуголовка зірчаста. 
В сфере падежных форм отмечается вариантность эпонимных обозначений. Латинские формы на -іa (Knipowischia, Sabanejewia) в украинской терминосистеме выступают в двух вариантах именительном и родительном падежах (с тенденционным доминированием последнего): бичок кніповичія, шипавка Сабанєєвія. Этот процесс идёт параллельно с наличием традиционно сохраняемых без изменения терминов-эпонимов: бичок Кесслера, бичок-пуголовоч Браунера, марена Валецъкого, морсъкий собачка Звонимира и т. д. Единственным логичным объяснением наметившегося явления может быть перевод видового названия в однокомпонентное родовое без указания на принадлежность к семье: Кніповичія, Сабанєєвія.

Возникновение лексических вариантов в украинской ихтиологической терминосистеме может быть обусловлено чисто субъективными факторами. Достаточно пронаблюдать за темпоральным и функциональным разнообразием названий игловых в украинской научной литературе: голки-риби (Російсько-український словник В. Жайворонка (2003) [4], голкові (“Фауна України» (1980), голкові, морсъкі голки (Ю. В. Мовчан. "Риби України» (2011) [3], ігличевi, іглищя в ихтиологической номенклатуре как советского [2], так и постсоветского периода [1]. В современных ихтиологических работах преимущественно используется специфическое украинское терминологизированное слово, хотя и от лексемы голка терминосистема не отказалась, отведя ей место в составе словосочетаний, например, триголокова колючка, багатоголкова колючка.

Лексическая вариантность проявляется и в массиве заимствованных терминов-варваризмов. Ихтионимы, как правило, адаптируются в двух формах — либо графической, либо словообразовательной и, как исключение, в виде вариантов (бичож-паганелюс и бичок-паганель). Подобное вариантное выражение может быть обусловлено воздействием закона аналогии, а поскольку и графическое, и словообразовательное освоение в украинской систематике представлено широко, причём не только на уровне рода, но и вида (паганель, пагель; мезогобиус, неогобиус, параблениус), то и вариантность подобного типа пока труднопреодолима. Столь же многотрудна и борьба с абсолютными синонимами. Эта проблема (о ней уже упоминалось выше) относится к числу актуальных задач, стоящих в равной мере как перед украиноязычной, так и перед русскоязычной терминологической системой.

Анализ интерлингвальных (украинских и русских) ихтионимов позволил выделить три основных способа проявления вариантности на межъязыковом уровне. Первый из них - варианты-корреляты. Под термином (корреляты) мы будем понимать ихтионимы, которые имеют одинаковый (эквивалентный) набор лексем-компонентов, вне зависимости от порядка следования частей: бубало малоротий - малоротый буфббало, харіус європейсъкий - европейский хариус.

Дивергенты полные - это специфические терминологические номинации в каждом отдельно взятом языке, явление, характерное для любой национальной терминосистемы: білизна - жерех, верховка - уклейка, клепець - белоглазка, меньок - налим, бабечь-головач - подкаменщик, марена звичайна - усач.

В плане сопоставления особый интерес представляют ихтионимы, являющиеся частичными дивергентами. $\mathrm{K}$ их числу следует отнести структурно-лексические русско-украинские варианты. Биномены, представленные в данной группе, могут быть сгруппированы по принципу родовой или видовой оппозиции.

Первый признак, характеризующий дивергенты по видовому компоненту, - это “наличие / отсутствие» видовой номинации в одном из языков: бычок- травяник (русск.) - бичок-трав'яник змієголовий (укр.), бычок-цуцык (русск.) - тупоносий бичок-цуцик (укр.). Объединение двух видов фбнта атлантическая и финта средизенноморская привело к созданию в русской терминологии компрессивной формы ббнта, в украинской - сохранилось видовое уточнение: gбiнта європейсъжа. Как видим, детализированные номинации оказались частотнее в украинской терминологии, обратное же явление нехарактерно, отмечаются лишь единичные случаи, например, рыбеи иерноморско-азовский (русск.) - рибець (укр.).

Видовой компонент может отличаться в двух языках и в семантическом отношении, хотя и в рамках описанного принципа стремления к уточнению понятия. Так, американский веслонос в украинской терминологии обозначается термином, уточняющим его локализацию: веслоніс північноамериканский.

Ещё одним способом усилить информативность термина в украинской терминосистеме является контаминация. То, что русскоязычной терминологии функционирует как частичные синонимы, в украинской порой принимает вид трёхкомпонентной единицы. Данное явление распространяется на значительное число таксономических номинаций: атлантический угорь, морской угорь (русск.) морсъкий вугор атлантичний; европейский угорь, речной угорь - річковий європейсъкий вугор; бычок-иуцык, тупоносый бычок (русск.) - тупоносий бичок иууик (укр.).

Лексические варианты видового компонента — результат национально-специфического видения мира. Данный тип соответствия точнее может быть определен как частичные синонимы, так как объекты называются по разным их признакам: сомик коричневий (укр.) - сомик американский (русск.); пузанок дунайский (укр.) - пузанок иерноморский (русск.); бичок хвостаи (укр.) - быиок Книповича (русск.). 
Однако следует отметить, что объективные результаты при анализе терминологической синхронии, можно получить лишь с подключением диахронического исследования. Несмотря на устоявшуюся в украинской систематике приверженность к многокомпонентным терминам, последние рекомендации для научных работников упрощают структуру ихтионима: „Видова назва не обов'язково включає в себе повну назву роду. Так, доцільними є назви видів роду Золотиста щипавка (Sabanejewia) з використанням лише слова „щипавка”: щипавка балканська (S. balcanica), щипавка болгарська (S. bulgarica), щипавка північна (S. baltica), оскільки ці назви не повторюють назв видів роду Щипавка (Cobitis). Те саме стосується кількох родів родини Собачкових (Blenniidae)» [1]. Если ранее термин включал сложное слово с уточняющим компонентом-пелагонимом: $n y з а н о к ~$ азовсъко-иерноморсъжий, - то теперь термин упрощается: пузанок азовсъкий. Трёхкомпонентный термин становится двухкомпонентным, а двухкомпонентный однокомпонентным (бичож мезогобіус жабоголовий - бичож-жаба).

Выводы. Итак, анализ синонимии и вариантности в ихтиологической систематике названий рыб Украины позволяет заключить, что наличие абсолютной и частичной синонимии в обоих языках вызвано объективными, однако различными по характеру причинами: в русскоязычной биологической терминосистеме - вследствие длительности функционирования, в украиноязычной - в силу незавершённости фазы становления и активности терминогенеза.

Лингвистический анализ любой национальной ихтиологической терминосистемы должен проводиться в неразрывном единстве синхронического и диахронического подхода к материалу. Диахронический аспект изучения украинской ихтиологической терминологии позволяет утверждать, что современный процесс унификации и стандартизации названий рыб осложняется вследствие наличия двух противоречащих друг другу тенденций: с одной стороны, это стремление к информационной насыщенности терминологических номинаций и тяготение к аналитическому словообразованию, а с другой, к экономии языковых средств и упрощению семантической и структурной организации ихтионимов.

Литература

1. Куцоконь Ю. Українські назви міног і риб фауни України для наукового вжитку/ Ю. Куцоконь, Ю. Квач // Біологічні студії. - 2012. - Т. 6. № 2. - С. 199-220.

2. Маркевич О. Російсько-українсько-латинський воологічний словник : термінологія і номенклатура / О. Маркевич, К. Татарко. - К. : Наук. думка, 1983. - 411 с.

3. Мовиан Ю. В. Риби України / Ю. В. Мовчан. - К. : Золоті ворота, 2011. - 444 с.

4. Російсько-український словник / [за ред. В. В. Жайворонка]. - К. : Абрис, 2003. - 1424 с.

\section{References}

1. Kutsokon', Yu., Kvach, Yu. (2012), "Ukrainian names of lampreys and fishes of the fauna of Ukraine for the scientific use", Studia Biologica [Ukraïns'ki nazvy minog i ryb fauny Ukraïny dlia naukovogo vzhytku, Biologichni studiï], Lvov Franko National University, Lvov, vol. 6, No 2, pp. 199-220.

2. Markevich, O., Tatarko, K. (1983), Russian-Ukrainian-Latin zoological dictionary : terminology and nomenclature [Rosijs'ko-ukraïns'ko-latyns'kyj zoologichnyj slovnyk : terminologija i nomenklatura], Naukova Dumka, Kyiv, $411 \mathrm{p}$.

3. Movchan, U. V. (2011), Fishes of Ukraine [Ryby Ukrainy], Zoloti vorota, Kyiv, 444 p.

4. Zhajvoronok, V. V. ed. (2003), Russian-Ukrainian dictionary, [Rosijs'ko-ukraïns'kyj slovnyk], Abrys, Kyiv, $1424 \mathrm{p}$.

IIIУМАРІНА Тетяна Федорівна,

кандидат філологічних наук, доцент кафедри російської мови

Одеського національного університету імені I. I. Мечникова;

Французький бульвар, 24/26, Одеса, 65058, Україна, e-mail:shumarina2010@mail.ru;

тел.: +38(048)683539; моб.: +38 067 3779936; ORCID ID: 0000-0001-7383-7707

\section{НОМЕНКЛАТУРНІ СИНОНІМИ І ВАРІАНТИ ТАКСОНІВ В ІХТІОЛОГІЧНІЙ СИСТЕМАТИЦІ (НА МАТЕРІАЛІ НАЗВ РИБ УКРАЇНИ)}

Анотація. У статті зіставлено одну із груп сучасних української та російської іхтіономічних систем. Мета статті - виокремити сучасні мовні тенденції в національних (російській та українській) таксономіях. Об'єктом вивчення в роботі є біологічна номенклатура, предметом дослідження - номенклатурні номінації таксонів риб України. У роботі використано описовий та зіставний методи. У результаті дослідження виявлено варіанти та синоніми термінів, тотожність і розбіжності у вернакулярних номінаціях риб. Висновки. Наявність абсолютної та часткової синонімії, а також варіантності в обох мовах вмотивовано екстралінгвістичними та інтралінгвістичними факторами. Сучасний процес уніфікації та стандартизації назв риб ускладнено за наявності двох протилежних тенденцій. Ономасіологічні тенденції в національних іхтіологічних терміносистемах суперечливі: з одного боку, це тяжіння до аналітичного словотвору, а 
з іншого, - до економії мовних засобів і спрощення семантичної та структурної організації іхтіонімів. Практична цінність результатів дослідження полягає в можливості використання їх у практичній та теоретичній систематиці іхтіофауни України.

Ключові слова: номенклатура, термін, іхтіонім, варіант, синонім.

Tatiana F. SHUMARINA,

PhD (Philological Sciences), Associate Professor of the Russian Language Department of Odessa I. I. Mechnikov National University;

24/26 Francuzskij blvd., Odessa, 65058, Ukraine; e-mail: shumarina2010@mail.ru;

tel.: +38(048)683539; mob.: +38 067 3779936; ORCID ID: 0000-0001-7383-7707

\section{NOMENCLATURE SYNONYMS AND VARIANTS OF TAXONS IN THE ICHTHYOLOGICAL SYSTEMATICS (ON THE MATERIAL OF THE NAMES OF FISHES OF UKRAINE)}

Summary. The article describes the terminological vocabulary used in modern Ukrainian and Russian Ichthyological taxonomies. The purpose of this article is to identify current trends in the national language (Russian and Ukrainian) taxonomies. The object of study in the present work was the biological nomenclature; research subject - the nomenclature nominations of fishes of Ukraine. Descriptive and comparative methods were used. As a result, the study identifies variants and synonyms of the terms, the similarities and differences in vernacular nominations of fish. Conclusions. The presence of an absolute and partial synonyms, as well as the variance in both languages due to extralingual and intralingual factors. Modern processes of unification and standardization of fish names complicated due to the presence of two conflicting trends. Onomasiological trends in national systems of ichthyological terms are contradictory: on the one hand, this is an attraction to the analytical word formation, and on the other - to save linguistic resources and simplify the semantic and structural organization of these terms. The practical value of the results of the study lies in the possibility of their use in practical and theoretical taxonomy of the fish fauna of Ukraine.

Key words: nomenclature, the term, ichthyonym, variant, synonymous.

Статтю отримано 22.09.2017 p.

http://dx.doi.org/10.18524/2307-4558.2017.28.115844

УДК [811.161.1+811.163.2+811.14'06]'367.4'373.611/.612

КЂНЕВА Виктория Гочева,

доктор по филология, главен асистент, катедра „Класически и източни езици и култури“,

Великотърновски университет „Св. св. Кирил и Методий“; гр. Велико Търново, 5003, България; тел.: +359 885149 429; e-mail: vgotcheva_g@mail.bg; ORCID ID: 0000-0003-1103-3054

\section{СЪКРАТЕНИТЕ НОМИНАТИВНИ ЕДИНИЦИ В КОНТЕКСТА НА ОТНОШЕНИЯТА „ЕКВИВАЛЕНТНОСТ - БЕЗЕКВИВАЛЕНТНОСТ“. УНИВЕРБИЗАЦИЯ (ВЪРХУ МАТЕРИАЛ ОТ БЪЛГАРСКИЯ, РУСКИЯ И ГРЪЦКИЯ ЕЗИК)}

Анотация: Целта на настоящата статия е анализ на универбизацията в светлината на отношенията еквивалентност - безеквивалентност. Обект са универбатите от гледище на ролята им за появата на лакуни в руския, българския и гръцкия език. Основен метод на изследване е съпоставителният. Резултатите от анализа показват, че спецификите, които притежава всеки от трите езика, неминуемо водят до разлики както в граматичните, така и в лексикалните им системи. Съпоставката и анализът на универбатите на трите сравнявани езика дава представа за възприемането и интерпретирането на фактите от реалната действителност от страна на всеки един от тези три народа. Основният извод е, че универбизацията като явление, обусловено от екстралингвистични фактори и зависещо изцяло от конкретните езикови средства, в определени случаи е причина за констатирано наличие на „бели петна“при езикова съпоставка и/или превод. Практическото значение на представения анализ е свързано преди всичко с теоретичните и практическите проблеми на превода. език.

Ключови думи: универбизация, еквивалентност, безеквивалентност, лакуна, руски език, български език, гръцки

Поставяне на проблема. Формирането на нови понятия, отразяващи новопоявили се предмети, явления или обществени отношения, води до необходимост от тяхното назоваване и съответно от създаване на нови номинативни единици ${ }^{1}$, които да запълват „празните места“в речниковия състав на съответния език.

${ }^{1}$ За понятието номинативна единица и за неговото разбиране, както и за видовете номинативни единици вж. [8]. 